\title{
Learning vocabulary through image sketching among primary school children.
}

\begin{abstract}
Vocabulary has long been neglected by most linguists and language teachers who either regard the teaching of it as unnecessary or even determined to the learning of a second language. In recent years, however, interest in the teaching/learning vocabulary has revived and once again a number of linguists and language teachers are involved in attempts to facilitate vocabulary acquisition by the foreign learner of English. This paper introduces a technique of teaching/learning vocabulary that aims to make the task not only more enjoyable for both teacher and learner but also more meaningful. The technique in question is a variation of the so-called mnemonic techniques which seek to create an unusual association between the word form and its meaning. But the technique differs from the keyword technique in important ways. First of all, it makes no attempt to establish any link between the learner's first language and English. Secondly, it involves the learners taking time - about 2 or 3 minutes - to sketch an image of the word or expression under study. The programme requires the retraining of service teachers who are provided with draw upon their experience in conducting of 20 students in Sek.Keb.Serdang, Selangor. The feedback received from the students supports the vocabulary programmes from image sketching.
\end{abstract}

Keyword: Vocabulary; Image sketching; Primary school children. 